\title{
LOS ARTISTAS CORTESANOS EN LA CONCEPCIÓN DEL NUEVO TRONO DE LA VIRGEN DEL SAGRARIO DE TOLEDO: REVISANDO TÓPICOS
}

\author{
LAURA ILleSCAS DÍAZ ${ }^{1}$ \\ Licenciada en Historia del Arte, Universidad de Salamanca
}

\begin{abstract}
El trono de la Virgen del Sagrario se alza como un testimonio único de la platería barroca en nuestra geografía. Por decisión del prelado, Baltasar de Moscoso y Sandoval, en su concepción y posterior hechura participaron artistas del prestigio de Alonso Cano, Pedro de la Torre, Francisco Bautista, Sebastián de Herrera Barnuevo y Virgilio Fanelli, habiendo sido objeto de estudio en numerosas publicaciones. No obstante, el hallazgo de documentación inédita en el Archivo Capitular de Toledo nos ha brindado la oportunidad de subsanar ciertos errores que se cernían sobre la secuencia de hechos acaecidos, así como de matizar con mayor rigor en qué consistió la intervención de cada uno de los citados maestros y la fase en que esta se produjo.

Palabras clave: Trono; Virgen del Sagrario; Catedral de Toledo; Sebastián de Herrera Barnuevo; Pedro de la Torre; Alonso Cano; Francisco Bautista.
\end{abstract}

\section{COURTLY ARTISTS IN THE CONCEPTION OF THE NEW THRONE OF THE VIRGEN DEL SAGRARIO DE TOLEDO: REVIEWING TOPICS}

The throne of the Virgen del Sagrario is a unique testimony of the Baroque silverware in our geography. The prelate, Baltasar de Moscoso y Sandoval, decided that the most famous artists, such as Alonso Cano, Pedro de la Torre, Francisco Bautista, Sebastián de Herrera Barnuevo and Virgilio Fanelli, participated in its conception and subsequent creation. Although this has been the subject of study in the many publications, thanks to the discovery of unpublished documentation in the Capitular Archive of Toledo, today we can correct some errors related to the sequence of events. We can also clarify the role of each artist and the phase in which they worked.

Key words: Throne; Virgen del Sagrario; Toledo Cathedral; Sebastián de Herrera Barnuevo; Pedro de la Torre; Alonso Cano; Francisco Bautista.

Cómo citar este artículo / Citation: Illescas Díaz, Laura (2020) "Los artistas cortesanos en la concepción del nuevo trono de la Virgen del Sagrario de Toledo: revisando tópicos”. En: Archivo Español de Arte, vol. 93, núm. 372, Madrid, pp. 347-358. https://doi.org/10.3989/aearte.2020.23.

\section{Los albores del proceso: el concurso en la capital}

En 1646 Baltasar de Moscoso y Sandoval fue nombrado arzobispo de Toledo, año en que la fábrica catedralicia se hallaba sumida en la construcción de la capilla de las Reliquias, conocida popularmente como "capilla del Ochavo". En esta realidad, el prelado hubo de pensar en nuevas empresas artísticas en las que poder alzarse como su principal impulsor y, al igual que sus ante-

\footnotetext{
1 laura.illescasdiaz@gmail.com / ORCID iD: https://orcid.org/0000-0002-8081-2935
} 
cesores en el cargo, dejar su impronta en el templo primado, volviendo su atención a la venerada imagen de la Virgen del Sagrario. Pese a que ya disfrutaba de un opulento espacio revestido de mármoles y decorado por los más prestigiosos pintores, lo cierto es que continuaba asentada en un antiguo trono de plata que rompía la magnificencia del conjunto y no lograba transmitir al fiel-espectador su elevado peso simbólico, lo que para el prelado se convirtió, sin duda, en una oportunidad idónea de satisfacer su propósito. Así pues, en los primeros meses de su mandato comunicó al cabildo su deseo de resolver tal carencia con la hechura de un nuevo trono de mayor envergadura y concebido bajo los preceptos del lenguaje estético coetáneo, dejando noticia de ello su biógrafo, fray Antonio de Jesús María:

Con ocasión de acudir algunos días a ver la Obra (del Ochavo), i con las frequentes Visitas, que por la Tribuna de su Palacio hacia á Nuestra Señora del Sagrario (copia la mas favorecida de su Original, que la Cristiandad venera) notó, que el Trono, que la sustentaba, era menos Magestuoso, de lo que pedia la Soberania de la Emperatriz de los Angeles. Resolvióse, a que se hiciese Otro, como convenia, i decia, quando lo trataba: que aunque la Fabrica estaba mui empeñada con la Obra de la Capilla de las Reliquias, cediendo la del Trono de Santa Maria Santissima tan en honra suia, i la de su Hijo, no havia sino comenzarle, confiando, que Hijo, y Madre le acabarian².

La elección del modelo inauguró un largo y lento proceso que se dilató por varios años y generó una copiosa documentación, publicada en su mayoría por Manuel Remón Zarco del Valle y Francisco Pérez Sedano, así como por autores más recientes como, Virginia Tovar, Juan Nicolau Castro, Fernando Marías o José Manuel Cruz Valdovinos, lo que explica su protagonismo en una amplia variedad de trabajos científicos ${ }^{3}$. No obstante, gracias a una nueva revisión de los fondos del Archivo Capitular de Toledo y el consiguiente hallazgo de documentación inédita, hemos logrado dar respuesta a ciertas incongruencias que venían reiterándose y organizar con mayor rigor la secuencia de los hechos acaecidos. Para ello, volvemos a tomar como punto de partida la obra del religioso, donde se informa de las gestiones necesarias en la búsqueda del candidato idóneo:

Mandò a D. Pedro de Inarra, Obrero Maior, escribiese á Madrid, para que los Maiores Artifices hiciesen (conformándose con las medidas del Sitio, en que está la Imagen) varios Diseños; i despues se confiriesen, y se eligiese el que parecese mejor. Se "consultó a los Maestros de obras del Rei y otros grandes de la Corte acerca del trono que se trazaba, y todos juntos, en presencia del Cardenal, vieron y confirieron los rasguños que habían dibujado el Hermano Francisco Bautista, de la Compañía de Jesús, y Pedro de la Torre insignes Arquitectos, y cotejados con otros de don Sebastián de Herrera y Alonso Cano, eminentes en Pintura y Arquitectura se eligió el que pareció mejor. Deste, mandó D. Baltasar, abrir lámina y la imprimión .

Fray Antonio de Jesús María fechó este concurso en 1648 y así lo han reiterado aquellos trabajos que nos preceden, sin haber considerado que el texto presenta múltiples errores en cuanto a las dataciones, siendo necesarios otros testimonios con los que poder cotejarlas y determinar si son o no ciertas 5 . En los libros de Frutos y Gastos ya se constata la presentación y aceptación de unas trazas de Pedro de la Torre en $1647^{6}$, y su posterior hechura en plata por el maestro Cristóbal de Pancorbo

\footnotetext{
2 Antonio de Jesús María, 1680, párrafo, 1346.

3 Tovar, 1975: 197; Nicolau, 1996: 279; Marías,1999: 291-322; Cruz, 1985:1253. Al margen de los trabajos concernientes a los autores citados véanse, también: Fernández; Rodríguez; Castañeda, 2009: 22, 23 y 53; Díaz, 2010: 62; Lamas, 2016: 221, 222 y 240

4 Antonio de Jesús María, 1680: párrafo 1358.

5 Recordemos que el fraile fija en 1648 el inicio de las gestiones concernientes a la fábrica del trono, cuando sabemos que el 28 de diciembre de 1647 Pedro de la Torre ya cobró por la hechura de unas trazas, como veremos en el cuerpo de texto más adelante. Asimismo, comete otro error al situar a Virgilio Fanelli en 1652 ya en la Península, fecha en la que aún residía en Génova. Véase en: Bulgari, 1974: 164; Condorelli, 1994: 578.

${ }^{6}$ Cruz: 1985: 1253.
} 
en $1648^{7}$, como veremos, por lo que hoy formulamos esta cuestión: ¿no resulta un tanto extraño convocar un concurso destinado a la presentación de nuevos modelos para el trono cuando se habían iniciado ya las gestiones para la factura de otro? Al contrario de lo que se ha venido sosteniendo, parece más acertado pensar que dicho concurso se fijaría al inicio del proceso, es decir en el año 1647; sería entonces cuando Pedro López de Inarra Isasi se dirigió a la capital con el propósito de reclamar la participación de los "maiores artífices". Este nuevo enfoque no solo se ajusta más a los registros hallados, sino que también permite trazar una secuencia de los hechos más lógica.

\section{Proyectos presentados: Alonso Cano y Pedro de la Torre}

Planteada esta primera cuestión, retomamos nuestro recorrido en 1647 y el efecto que tuvo la llamada en el círculo artístico de la Corte. La oportunidad de entrar al servicio del templo primado y vincularse a un proyecto de semejante envergadura suponía, grosso modo, el ascenso profesional para cualquier maestro y el consiguiente reconocimiento de su labor; era, a todas luces, una ansiada meta a la que dos artistas optaron, Pedro de la Torre y Alonso Cano. No obstante, el fraile carmelita recoge también los nombres de Francisco Bautista y Sebastián de Herrera Barnuevo, razón por la que se les ha considerado hasta el momento oponentes en el dicho concurso. ¿Fue realmente así? Parece que no. De acuerdo al enfoque aquí propuesto, dos fueron los participantes, el granadino y el de ascendencia conquense, mientras que la intervención del resto se fijaría en fechas posteriores, como veremos. Ambos entroncaban en esta corriente inaugurada por Creszenzi en la construcción del Real Panteón, donde primaba el conocimiento de la teoría arquitectónica, el dominio del dibujo y la capacidad inventiva, de modo que, su perfil profesional, ampliamente conocido, les convertía en candidatos idóneos para afrontar el reto que llegaba desde la Primada ${ }^{8}$.

De estos dos proyectos iniciales, comenzaremos por aquel que no logró convencer al prelado, el concebido por Alonso Cano, hoy conservado en el Archivo Capitular [fig. 1]. Desde los albores del siglo XX se ha mantenido la teoría de que la fábrica catedralicia encargó al platero Joaquín de Pallarés, oriundo de Barcelona ${ }^{9}$, unas trazas para el trono, basándose para ello en un pago de 500 reales recibido el 28 de junio de 1647 "por su viaje a Madrid que vino llamado y trujo unas trazas para el trono de Nuestra Señora" ${ }^{10}$. Según argumentan sus defensores, estas tuvieron buenas críticas y consiguieron la aprobación de Baltasar de Moscoso y Sandoval, por lo que se procedió a elaborar un memorial para ser enviado a Roma, posiblemente en busca del beneplácito del aquellos eruditos y artistas vinculados a la corte papal, conocedores de la vanguardia. La ausencia de menciones posteriores hizo suponer que este primer modelo fue desestimado ${ }^{11}$.

\footnotetext{
7 Esta cuestión se verá con mayor detenimiento en el apartado $n^{\circ} 3$, si bien dejamos ya señalada la referencia documental: Decretos, cartas de pago y libramientos del Arzobispo Baltasar de Moscoso y Sandoval, Archivo Capitular de Toledo (ACT), Libro de Decretos, s/f.

${ }^{8}$ El perfil profesional de esta pareja se ciñe al grupo de los "arquitectos-artistas", por tanto, con amplio dominio del dibujo. De la extensa lista de trabajos que abordan esta cuestión haremos una selección de aquellos más destacados: Martín, 1958: 125-142; Tovar, 1981: 297-317; Blasco, 2013; Blasco, 2016: 279-306.

${ }^{9}$ Cuando en 1639 fue aprobado en Madrid como maestro platero dijo llamarse Juan, de ahí el uso de dicho nombre en las publicaciones posteriores. No obstante, el profesor Juan Nicolau transcribió el registro de varios pagos conservados en el Archivo Capitular de Toledo donde aparece como Joaquín, subsanando el posible error. Trabajos más actuales, como los de Juan María Cruz Yábar o Juan Luis Blanco Mozo, se dirigen a dicho platero como Joaquín Pallarés y no como Juan, de ahí que en el presente trabajo hallamos seguido su estela. Véase en Nicolau, 1995: 275; Blanco, 2009: 147-164; Cruz: 2016: 126. En cuanto a su participación en la hechura del trono, Rafael Ramírez de Arellano elabora un escueto recorrido por las noticias que le precedían. Informa cómo Pallarés fue "vecino de Madrid, que hizo uno de los proyectos para el trono de la Virgen del Sagrario, de Toledo, en 1640, según Ceán, en 46 según Llaguno-Ceán y Pérez Sedano, y en 1656 según D. Sixto Ramón Parro". Es decir, recoge las diversas fechas en las que, según estos autores, entregó las trazas a la fábrica catedralicia. Véase en Ramírez de Arellano, 1915: 326.

10 Frutos 1646 / Gastos 1647, ACT, Obra y Fábrica, fol. 79 r.

11 Rafael Ramírez de Arellano en su estudio dice: "pidió diseños, y un platero de Madrid, llamado Juan de Pallarés (se refiere a Joaquín) presentó un modelo que no debió ser del agrado del prelado, porque no se volvió a hablar de él”, información que ha venido repitiéndose hasta el presente trabajo. Véase en Ramírez de Arellano, 1915: 129.
} 


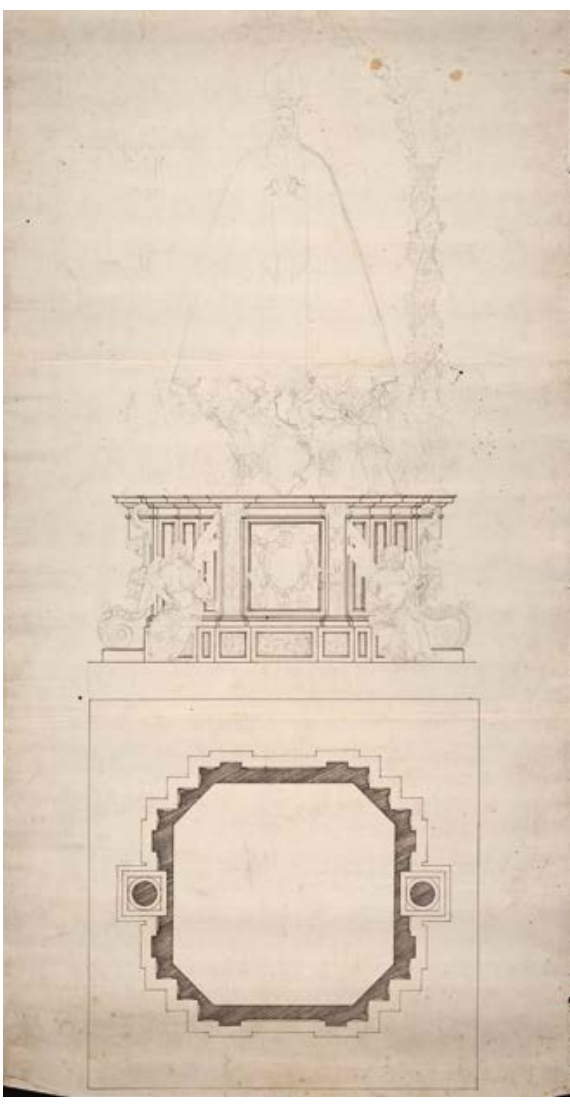

Fig. 1. Alonso Cano, Modelo para el trono de la Virgen del Sagrario, Dibujo a lápiz y pluma, Archivo Capitular de Toledo.
Pese a trabajar próximo al círculo de Felipe IV, lo cierto es que Joaquín de Pallarés no gozaba de un elevado prestigio, así como tampoco destacaba por un dominio del dibujo o de la arquitectura, en definitiva, su perfil no se ajustaba al término de "grandes artífices" recogido por el fraile carmelita ¿cómo encajar su presencia en el ambiente artístico de la Primada? La respuesta vino dada por Juan María Cruz Yábar ${ }^{12}$. Este historiador descarta a Joaquín de Pallarés como autor de las dichas trazas y, por el contrario, defiende la correspondencia de estas con Alonso Cano, quién desde la capital las habría enviado a Toledo por medio del citado platero bajo el argumento de una posible participación conjunta. Sabemos que ambos coincidieron durante la década de los 40 en la decoración del nuevo relicario del Alcázar madrileño ${ }^{13}$. Aunque desempeñando labores diferentes, lo cierto es que allí tuvieron la oportunidad de entrar en contacto y pensar en una colaboración para futuros encargos, como pudo suceder en el caso del trono toledano. Como prueba de ello, Cruz Yábar recurre a la inscripción incluida en las propias trazas: "a lo de acabar... sin quitar nada del intento a falta de lo quenta q. es el autor deste papel Alonso Cano en Madrid"; estas indicaciones irían destinadas a Joaquín de Pallarés, quien de este modo se comprometía a no introducir ninguna alteración y ceñirse al modelo ideado por su autor, es decir, Alonso Cano ${ }^{14}$. A sus argumentos añadimos lo que bajo nuestro criterio supone una interpretación equívoca del contenido; de acuerdo al registro del pago, el 28 de junio de 1647 la fábrica toledana pagó a Pallarés "por su viaje a Madrid que vino llamado y trujo unas trazas para el trono de Nuestra Señora" 15 , es decir, se le paga por traerlas desde la capital y no por hacerlas, de ahí que se haya considerado su autor y no su portador, como realmente fue.

Esta nueva lectura presenta una mayor coherencia en el modus operandi del prelado y la fábrica catedralicia pues, aunque el trono se hiciera en plata, extraña la intervención de Pallarés, maestro de segunda fila, para su concepción ${ }^{16}$. En base a ello, el devenir de los hechos hubo de ser el siguiente: en 1647 se publicó la convocatoria del concurso a la que Cano respondió ideando unas trazas, las que aquí nos ocupan, que serían trasladadas ese mismo año a Toledo por su compañero a fin de sembrar la posibilidad de que este se convirtiera en su ejecutor.

Llegados a este punto tan solo queda una última cuestión por resolver ¿cuál fue la cantidad percibida por Alonso Cano? Según los registros, el 17 de marzo de 1650 se le entregó la cantidad

12 Cruz, 2015: 127.

13 Sabemos que, bajo la dirección de Alonso Carbonel, este platero se encargó junto al ebanista Juan Sutil Cornejo de la construcción y ensamblaje de los muebles donde se custodiarían las piezas con los vestigios sagrados. Al parecer, el relicario se componía de dos estancias: la bóveda de la primera quedó decorada con una escena de la Asunción de la Virgen rodeada de las cuatro virtudes teologales y unos profetas, conjunto procedente de la mano de Félix Castelo y Jusepe Leonardo. Mientras, el techo de la segunda estancia, fue pintado únicamente por Félix Castelo. Ambas fueron tasadas por Alonso Cano, nombrado tasador por Felipe IV, y Luis Fernández nombrado por el citado pintor. Véase en: Blanco, 2009: 157.

14 Cruz, 2015: 127.

15 Frutos 1646 / Gastos 1647, ACT, Obra y Fábrica, fol. 79 r.

16 Véase en: Pérez, 2002: 122. 
de 1000 reales "por los pareceres y trazas que dexo en orden de las obras del Sagrario"17. El hecho de ser una fecha tan avanzada no debilita nuestro planteamiento ya que fue habitual la demora de la fábrica catedralicia a la hora de saldar sus cuentas con los maestros, circunstancia que vendría a explicar este desfase cronológico entre 1647, entrega de las trazas, y 1650, pago de las mismas.

El magistral dominio del diseño y la capacidad inventiva valieron al granadino para concebir un genuino modelo con el que buscaba acaparar la atención del prelado y que hoy, sin dudas, lo consigue con la nuestra ${ }^{18}$. La planta, reproducida a tinta en la zona inferior del papel, presenta un perfil octogonal de lados desiguales, recto en los frentes y truncado por tres diedros en los lados oblicuos, siendo estos últimos de menor longitud. Mientras, en los laterales se ubican los pedestales de perfil cuadrado donde se apoyarían las columnas, sobresaliendo levemente del contorno perimetral y provocando así cierto ensanchamiento.

El alzado nos descubre una imponente peana con marcado carácter arquitectónico, fruto de su formación en esta disciplina ${ }^{19}$. Con un manifiesto predominio de la línea recta, se integra por un pedestal decorado a base de tarjetas molduradas que alternan perfiles rectangulares y cuadrangulares, quedando su interior ocupado por elemento fitomorfos en recuerdo de aquellos presentes en los tejidos adamascados. El cuerpo principal, de menor anchura, se apoya en una suerte de basamento moldurado; el frontal rectangular del centro parece desplegarse hacia el fondo hasta culminar en los soportes de las columnas, generando un juego de volúmenes que acentúa la profundidad a la vez que aligera la impresión de bloque compacto. Dicho frontal se decora con una cartela moldurada y un escudo vacío de perfil ovalado, si bien el capelo cardenalicio y las borlas informan de su destino: albergar las armas de Baltasar de Moscoso y Sandoval con el propósito de informar al fiel-espectador sobre el auténtico promotor de la obra. El conjunto es flanqueado por dos franjas, también molduradas y rectangulares, aunque acusadamente más estrechas, donde se incrusta una suerte de enredadera vegetal con las hojas dispuestas hacia arriba.

A su vez, la estructura de la peana queda guarnecida por un corpus escultórico donde Alonso Cano plasmó nuevamente su impronta. En los laterales se sitúan cabezas de angelitos de las que penden racimos de fruta, rematados a su vez por una pareja de volutas cubiertas de vegetación. Flanqueando el escudo de armas, se contemplan a lápiz dos ángeles músicos sentados sobre la repisa cuyo aspecto muestra ciertas concomitancias con otros de su producción como La visión de San Juan Evangelista de Jerusalén (1635-1638) o Cristo muerto sostenido por un ángel (1646-1652), conservados hoy en The Wallace Collection y el Museo del Prado respectivamente. Al igual que en estos lienzos, aquí presentan un tamaño considerable que les confiere cierto protagonismo, reiterándose esa apuesta por anatomías esbeltas que, en este caso, apenas vislumbramos bajo la túnica. Las semejanzas continúan en ese abandono de la etapa infantil, con rasgos juveniles, tiernos y delicados, enmarcados por una cabellera lacia que desciende hasta los hombros y culmina en un sutil bucle rizado. Resulta interesante señalar las dudas que le surgieron a Cano en cuanto a su posición, concretamente la de aquel situado a la derecha, donde los pliegues de la túnica se funden con los arrepentimientos generados por la flexión de sus piernas.

Ciñéndose a ese gusto de origen medieval que abogaba por incluir ángeles músicos junto a María, ambos portan instrumentos ${ }^{20}$; a la izquierda, posada sobre el pecho y dispuesta en diagonal respecto al eje central, identificamos la viola da braccio, con su característica tapa de perfil cóncavo-convexo, las llaves en la parte central y el arco, apenas esbozado por las líneas del lápiz. Mientras, a la derecha se dispone el laúd, inconfundible por su caja de resonancia abultada en forma de media pera, mástil y clavijero en ángulo hacia atrás.

17 Frutos 1658 / Gastos 1659, ACT, Obra y Fábrica, fol. 86 r.

${ }_{18}$ Desde su descubrimiento en el ocaso del siglo XX, este dibujo raras veces ha conseguido el protagonismo merecido, exceptuando en el estudio de Fernando Marías que resultó, sin duda, un punto de inflexión para su conocimiento. Véase en Marías, 1999: 299.

19 Para abordar un estudio de la formación y práctica de Cano en el ámbito de la disciplina arquitectónica y su proyección en Madrid véanse, entre otros, los siguientes trabajos: Chueca, 1969: 11-127; Rodríguez, 2001: 375-392; Sánchez, 2001: 57-73; Bérchez, 2002: 61-85; Blasco, 2005: 127-150; Cruz (2014), pp. 191-222.

20 Para un mejor conocimiento sobre el tema, resulta de especial interés la lectura de los siguientes trabajos: Perpiñá, 2011: 397-411; Perpiñá, 2013: 29-49; 
En la zona superior de la peana se apoya un pedestal que evoca la estructura de un capitel, integrado por una base cuadrada y un tambor cuya anchura aumenta a medida que asciende; es circundado por una guirnalda de frutos, quedando el centro de su frente ocupado por un nuevo escudo de armas, también vacío, destinado probablemente a albergar el emblema de la Catedral Primada. Presenta un perfil ovalado de menor tamaño respecto al anterior, compuesto por cueros recortados que parecen evocar a aquellos frontispicios tan habituales en las portadas de tratados y obras literarias del siglo XVII.

El "capitel" se remata por una decena de querubines que conforman una suerte de nube destinada a ocultar el acoplamiento de la talla románica con la peana propiamente dicha. Al contrario que los músicos, éstos muestran rostros redondeados de eminente carácter infantil; sus diversas posiciones acentúan ese componente dinámico tan propio del gusto barroco y enlaza esta obra con otras de su producción donde nuevamente los incluye, siendo ejemplo de ello La Inmaculada Concepción (1648) o La Anunciación (1652), conservadas en el Museo Diocesano de Arte Sacro de Álava y en la Catedral de Granada respectivamente.

De los flancos de la peana emergen hacia las alturas una pareja de columnas salomónicas recubiertas de follaje que copian el modelo rubensiano, es decir, aquel configurado por cinco espiras y no seis como proponía el tratado de Los cinco órdenes de la Arquitectura de Jacopo Vignola, convertido en normativa en la geografía española tras su traducción al castellano por Patricio Cajés en el año $1593^{21}$. Esta apuesta de Alonso Cano parece derivar de su estancia en Madrid y el consiguiente aprendizaje de los círculos intelectuales y artísticos más selectos, siendo otro ejemplo la portada reproducida en una estampa conservada en la Biblioteca Nacional ${ }^{22}$. Aquí, la columna culmina en un capitel corintio donde se apoya el arco, de estructura lisa, sin molduras y recorrida en el intradós por cabezas de angelitos cuya fisionomía se asemeja a la de aquellos dispuestos en la nube. Mientras, en el extradós se dispone una crestería de la que apenas distinguimos su arranque y una suerte de corona o flor que actúa como remate.

Grosso modo, el modelo se integra por una sección inferior con predominio de la línea, en respuesta al gusto por el lenguaje clasicista, si bien la novedosa e imperante estética barroca hace a Cano jugar con los volúmenes de las secciones y su disposición. Este marcado carácter arquitectónico de la peana se desvanece en la sección superior, donde se asienta la Virgen del Sagrario, quizás debido al afán de evocar la idea de lo etéreo y divino en torno a su imagen. En efecto, Cano no solo optó por el orden salomónico y su línea curva, sino que eliminó el arquitrabe, obviando la transición lógica entre el capitel y el arco, como ya apunta Fernando Marías; además, tampoco hizo uso de molduras en la estructura de este último, lo que sin duda se hubiese ajustado más a la línea marcada en la peana y, por ende, conferido un empaque mayor. En su lugar, el granadino delegó el protagonismo en las cabezas de querubines, con las que de nuevo potencia ese componente etéreo del que hablábamos.

Pese a no convencer al prelado, lo cierto es que su condición de pintor-arquitecto junto a su elevada capacidad inventiva le hicieron concebir un modelo novedoso, fruto de esa reinterpretación del lenguaje arquitectónico clásico que experimentó tras su llegada a la capital, al igual que sucedió con otros modelos coetáneos de mayor envergadura como la Puerta de Guadalajara o el retablo de la iglesia de madrileña de San Juan de Dios, conservados estos dos últimos en una colección privada florentina y en el Museo Nacional del Prado, respectivamente. Los escasos autores que han deparado en el estudio de este trono mantienen, al igual que nosotros, que se trata de una obra cargada de elegancia y sofisticación donde, una vez más, quedó patente la huella de su ingenio.

21 Cajés, 1593.

22 El número de inventario de la dicha estampa es: DIB/16/39/32. En Madrid pudo verlo ejecutado en algunos retablos de Pedro de la Torre, quien precisamente se inclinaba por los fustes de cinco vueltas: "Y dichas columnas (salomónicas) han de tener cinco vueltas cada una... y en algunas partes donde se han ejecutado siendo del alto de seis... no han parecido bien, y esta opinión la observó en sus obras Pedro de la Torre, el mayor maestro que ha tenido España, que esto es notorio a todos los maestros de esta profesión”. Escritura de concierto de 1679 del retablo de la capilla de Santa Cruz en la catedral de Palencia. El fragmento ha sido tomado de Rodríguez, 2001: 384 y 385. 
Conocido el primer diseño presentado al concurso volvemos nuestra atención al segundo, procedente de Pedro de la Torre, desconociéndose a día de hoy su paradero ${ }^{23}$. ¿Por qué sabemos que fue él y no otro de los artistas citados? La respuesta la hallamos nuevamente en el Archivo Capitular. El 28 de diciembre de 1647 se pagó a dicho arquitecto ${ }^{24} 1650$ reales "por orden del Cardenal, por haçer la traça y dibuxo del santuario o trono de Nuestra Señora del Sagrario que vino a traer el dicho a esta ciudad" 25 . No obstante, la clave reside en el Decreto Arzobispal fechado el 10 de enero de 1648 :

Por la presente mandamos a D. Pedro Lopez de Ynarra canónigo de nuestra Santa Yglesia de Toledo y obrero maior della libréis en la hacienda de la obra a Pedro de Torre, architecto, vecino de la villa de Madrid ciento y cinquenta ducados por tantos en que se ajusto lo que hubo de aver por la traza que ha hecho para el trono de Nuestra Señora del Sagrario de la qual, se ha hecho elección para executarla y la tiene entregada. Yzome la razon D. Juan de Llano contador de la dicha obra. Dado en Toledo a diez de enero de mil seiscientos quarenta y ocho años ${ }^{26}$.

Al parecer, estos 1650 reales primeramente se entregaron al canónigo y, a posteriori, este se los dio al arquitecto madrileño; al margen del trámite económico, lo interesante es que el contenido señala que la dicha traza "se ha hecho elección para executarla". Tal y como ya adelantamos al inicio, esta debió ajustarse a las pretensiones del prelado y se procedió a su materialización en plata, confirmando de manera categórica nuestro planteamiento.

\section{El modelo elegido: su materialización en plata}

Los elegidos para tal propósito fueron el platero Cristóbal Pancorbo y el maestro de campanas Pedro de la Sota, quienes el 8 de agosto de 1648 procedieron a la firma del contrato, obligándose a la hechura del trono "según y como lo demuestra la planta y traça"27. Aunque no especifica que esta se debiese a Pedro de la Torre, la cláusula prosigue informando que fue entregada por "el dho señor Pedro de Inarra de su mano y la recivieron en las suyas los dhos maestros y quedaron con ella de que yo el dicho scrivano doy fe", es decir, la traza original fue trasladada al obrador. Esta apreciación resulta de gran interés pues viene a justificar el porqué se ha conservado en el Archivo Capitular la propuesta de Alonso y no la de este otro arquitecto pese a que ambas compitieron en 1647, una circunstancia que no hace sino confirmar, una vez más, nuestra hipótesis.

La pareja de artífices habría de entregar la pieza "acavada en toda perfecçion" en un plazo de tres años, sin poder ausentarse de la ciudad so pena de conseguir licencia de Baltasar de Moscoso y Sandoval. En caso de fallecimiento, los fiadores quedaban obligados a la contratación de otro maestro a fin de proseguir con su hechura y no interrumpir el ritmo de trabajo. A su vez, contarían con un grupo de doce oficiales elegidos en base a su pericia con el metal, siempre bajo el beneplácito del canónigo obrero o de los visitadores vinculados a la fábrica del trono.

Respecto a la cuestión económica se acordó lo siguiente: se les proporcionaría casa, obrador y cajones de madera, estos últimos para las fundiciones y vaciados, además de hacerles una entrega paulatina de la plata en función de los avances. No obstante, se especifica que el resto de "erramien-

${ }^{23}$ No se debe confundir con otra traza de él junto con Francisco Bautista, fechada en 1649.

${ }^{24}$ En el presente artículo se aludirá a Pedro de la Torre y Francisco Bautista como "arquitectos", teniendo en cuenta que dicho término en el siglo XVII no se corresponde con el significado actual, sino que hacía referencia a artífices especializados en la concepción de monumentos efímeros, construcciones en maderas y trazas decorativas.

25 Decretos, cartas de pago y libramientos del Arzobispo Baltasar de Moscoso y Sandoval, ACT, Libro de Decretos, s/f.

${ }^{26}$ En la escritura se cita la cantidad de 150 ducados, cuya conversión a reales suman los 1650 señalados. Véase en Decretos, cartas de pago y libramientos del Arzobispo Baltasar de Moscoso y Sandoval, ACT, Libro de Decretos, s/f.

${ }_{27}$ Archivo Histórico Provincial de Toledo (AHPT), Protocolo $\mathrm{n}^{\circ}$ 15835, fols. 967 r./975 v. Su conocimiento se lo debemos a Fernando Marías, quien hizo mención de ella por primera vez en: Marías, 1999: 291-322. 


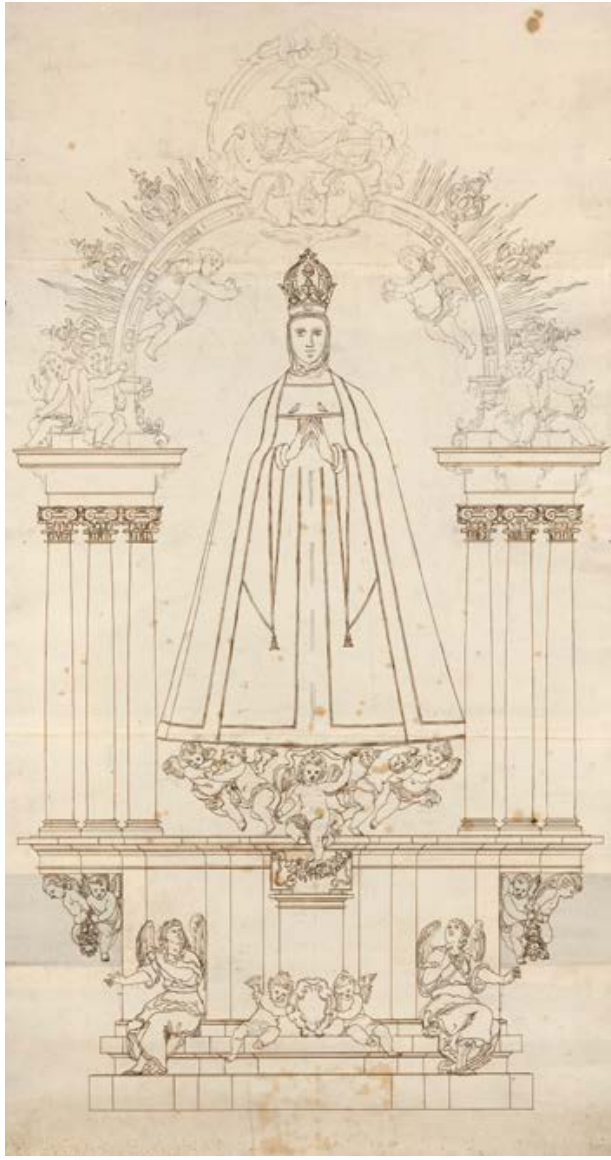

Fig. 2. Pedro de la Torre y Francisco Bautista,

Modelo para el trono de la Virgen del Sagrario, Dibujo a lápiz y pluma, Archivo Capitular de Toledo. tas, ynstrumentos y pertrechos necesarios" correrían por su costa. Al inicio del encargo recibirían 11000 reales "por quenta de su ocupacion y trabajo", y 5500 reales, al finalizar cada mes; esta última cantidad podría variar si aumentara o disminuye el número de oficiales, es decir, se efectuaría un reajuste de modo que lo recibido fuese siempre proporcional.

Abogando por el mejor resultado, en la cláusula décimo primera se contempla la posibilidad de introducir cambios durante el proceso: "se reconoziere se puede mejorar de adorno y obras aunque sean distintas de las que significa y demuestra la dha traça queda en eleccion de su Eminencia disponer y mandar en esta parte lo que mas fuere de su servicio y quanto ordenare y mandare lo an de executar y executaran los dhos maestros". Una vez concluida, la obra se tasaría por personas peritas en el arte de la platería, especificando que dicha tasación no habría de ser por peso de marco, sino midiendo el "balor de cada pieza y de por sí, y de todo lo obrado por junto", opción de la que solían beneficiarse estos últimos.

Poco hubo de avanzar la hechura de esta pieza. La falta de convicción que denotaba la cláusula destinada a la inclusión de mejoras auguraba cambios y éstos llegaron en 1649, es decir, un año más tarde, cuando el prelado paralizó el proceso y rechazó el modelo elegido ${ }^{28}$. ¿Cuál fue el detonante para tomar tan drástica medida? La respuesta viene dada por la presentación de un nuevo modelo por Pedro de la Torre y Francisco Bautista, hoy conservado en el Archivo Capitular de Toledo [fig. 2].

\section{La elección del modelo definitivo}

A priori, al lector le puede resultar un tanto extraño semejante cambio de rumbo e incluso, puede llegar a pensar que el modelo concebido por esta pareja de arquitectos se trate realmente del presentado por Pedro de la Torre en solitario en 1647, más aún cuando no incluye ninguna inscripción alusiva a su autoría, como sí sucedía en el caso de Alonso Cano ¿Cómo probar que estamos en lo cierto? La respuesta viene dada gracias al hallazgo de dos grabados fechados en 1649, ambos procedentes del artista flamenco Juan de Noort. En el primero de ellos, conservado en el convento toledano de las Capuchinas, se reproduce el trono junto a la inscripción en castellano "Francisco Bautista, de la Compañía de Jesús y Pedro de la Torre, arquitectos reales lo realizaron". Ante la imposibilidad de abordar su análisis a causa de su deplorable estado ${ }^{29}$, lo haremos con el segundo, del cual existe una copia en el Archivo Capitular de Toledo [fig. 3]. En él se incluye tan solo una imagen parcial del trono dedicada a la planta y alzado de la peana, junto a la inscripción latina: "Juan de Noort sculpsit Matriti Anno 1649. Fraciscus Baptista è Societate Jesu, et Petrus de la Torre in Regia Curia Architecti adinvenerunt”.

\footnotetext{
${ }^{28}$ Llegados a este punto del recorrido cabe recordar que los trabajos publicados hasta el momento defienden una hipótesis diversa a la aquí propuesta y ubican en 1648-1649 la convocatoria del concurso.

${ }^{29}$ El profesor Juan Nicolau lo dio a conocer por primera vez en: Nicolau, 1996: 276.
} 
Fig. 3. Juan de Noort, Modelo para el trono de la Virgen del Sagrario de Pedro de la Torre y Francisco Bautista, Grabado, Archivo Capitular de Toledo.

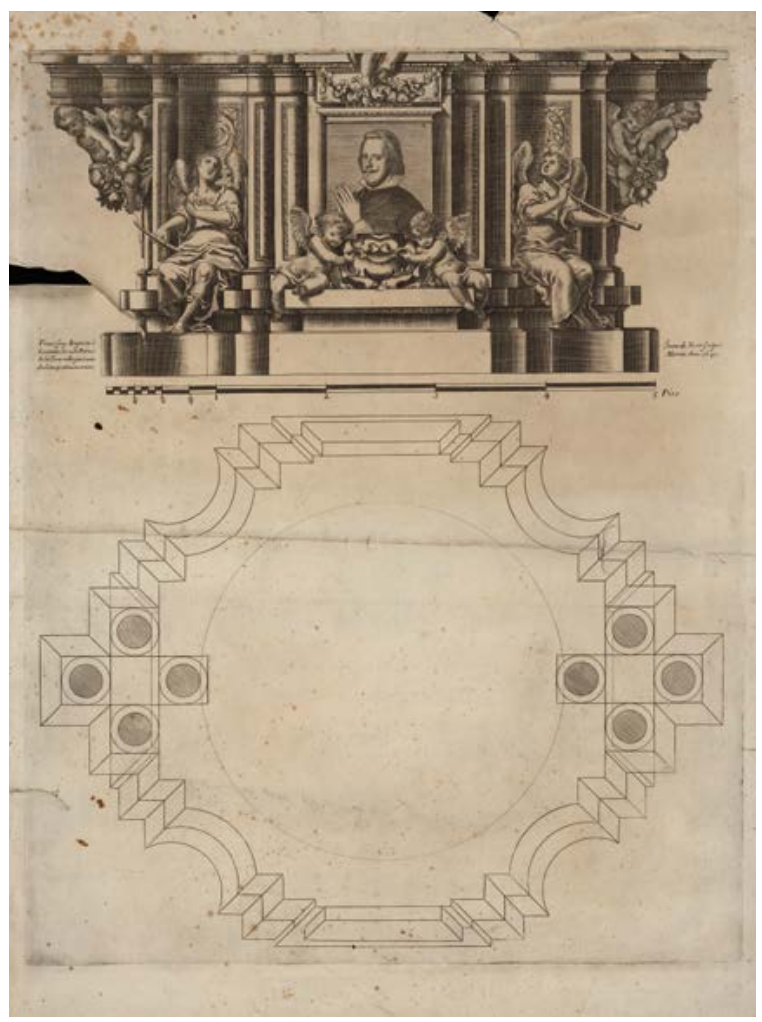

Juan Nicolau Castro y Fernando Marías ya señalaron las evidentes analogías entre la planta y peana del dibujo y aquellas reproducidas en el grabado, lo que les condujo a confirmar de manera categórica que se trataba de la misma pieza y, por ende, adjudicar su autoría a Pedro de la Torre y Francisco Bautista ${ }^{30}$. Así pues, sabemos que en 1649 ambos presentaron un modelo, aquel que conquistó definitivamente al prelado.

Su estructura se ciñe a la del baldaquino ahuecado que tanta popularidad alcanzó a partir de la segunda mitad del XVII en España, si bien en este caso, la formación y experiencia como retablistas de sus autores se dejó sentir en el empleo y disposición de los elementos. El trono se inicia por un basamento de escasa altura fragmentado por líneas perpendiculares en correspondencia con las aristas; le sigue el cuerpo de la peana propiamente dicha, con tantas secciones como las marcadas en el dicho basamento, siendo de mayor anchura el paño central, quizá por estar destinado a albergar alguna escena del programa iconográfico. Mientras, en la parte inferior dos ángeles niños sostienen un escudo de armas vacío. Este conjunto es flanqueado por otra pareja de ángeles cuyo aspecto remite al que presentaban aquellos concebidos por Alonso Cano en su propuesta, es decir, con un tamaño mayor, cuerpo esbelto y rasgos propios de la juventud. El corpus escultórico de este primer plano de la peana culmina con un trío de ángeles, de los que tan solo observamos dos, dispuestos bajo los salientes de los lados, simulando ménsulas.

Ya en el plano intermedio, se dispone un sencillo basamento y dos parejas de tríos de columnas, de fuste liso, con éntasis y rematadas en capitel compuesto, unidas en su parte superior por el correspondiente entablamento. La estructura prosigue con la presencia de un cuerpo de perfil octogonal; su

${ }^{30}$ El profesor Fernando Marías va más allá en sus concreciones y se atreve a fijar el cometido de cada uno de los grabados en las distintas fases del proceso ejecutivo. Según informa, aquel conservado en el Archivo Capitular se trataría de una mera prueba, mientras que el del convento de Capuchinas sería el definitivo, es decir, el que Baltasar de Moscoso y Sandoval mandó imprimir sobre raso y entregarlo a Felipe IV a modo de obsequio. Véase en: Nicolau, 1996: 276; Marías, 1999: 291-322. 
cuello mengua al crecer en altura y desemboca en el arranque del arco, sirviendo de asiento a dos parejas de ángeles niños dibujados a lápiz, también con cuerpos rollizos, rostros redondeados y cabellera corta y rizada. Por su parte, el arco de medio cañón se integra por dos secciones, una lisa, y otra decorada con motivos rectangulares y parejas de cuadrados; el extradós es recorrido por una peineta que se alterna con quintetos de rayos con la secuencia: flameado-recto, siendo el de mayor longitud aquel situado en la posición central. De la clave emerge una suerte de cuenco integrado por hojas y cueros recortados, a su vez rematado por dos volutas y una cabeza de angelito en su sección inferior; mientras, la sección superior se cubre por una triple moldura. En el interior se ubica Dios Padre en una posición de tres cuartos, cuya figura fue elaborada mediante trazos rápidos en los que Pedro de la Torre y Francisco Bautista olvidaron la meticulosidad de la parte arquitectónica, de ahí la falta de proporción entre las manos y el resto de la anatomía o la ausencia de precisión a la hora de reproducir la indumentaria. En el mismo eje, pero ya en el intradós, se posa la paloma del Espíritu Santo con las alas extendidas en posición frontal, flanqueada a su vez por una pareja de ángeles niños.

El centro de la composición queda ocupado por la talla románica, apoyada en una estructura con forma de luneto invertido recubierta en su totalidad por un quinteto de ángeles. Aquel situado en posición sedente porta entre sus manos un paño, a modo de filacteria, lo que abre la posibilidad de que estuviese reservado para una futura inscripción. Las parejas de ángeles que lo flanquean presentan actitudes con mayor dinamismo, se apoyan unos sobre otros a fin de aunar sus esfuerzos y simular de este modo la elevación de la Virgen hacia los cielos.

\section{Sebastián de Herrera Barnuevo y su cometido en el trono catedralicio}

Desde la publicación del hispanista Harold E. Wethey a mediados del siglo XX, la participación de Sebastián de Herrera Barnuevo en la fábrica del trono mariano ha suscitado un gran interés a la par que incógnitas ${ }^{31}$. Según los registros, cobró de la fábrica catedralicia la cantidad de 200 reales el 14 de febrero 1655 por "hacer una traza para el trono en oposición de la que hicieron Pedro de la Torre y el Padre Baptista" 32 . Por consiguiente, los trabajos precedentes sostienen que este entregó un modelo destinado a competir con aquel concebido por los citados arquitectos, si bien fue finalmente desestimado ${ }^{33}$. Recordemos que, para esa fecha, Pedro de la Torre ya había entregado la maqueta en madera correspondiente a su diseño, elegido de manera definitiva 6 años atrás. Asimismo, su materialización en plata le había sido confiada al platero italiano Virgilio Fanelli, quien firmó la escritura de concierto el 8 de enero de 1655 ante el escribano Rodrigo Alonso de $\mathrm{Hoz}^{34}$. Un modo de proceder un tanto incongruente que hoy nos hace preguntarnos ¿Por qué iba a solicitar el prelado un nuevo modelo en una fase tan adelantada del proceso? Sin duda, esta secuencia de hechos se torna ilógica y, por tanto, merecedora de una relectura.

La respuesta a tal complejo dilema viene dada gracias al hallazgo de parte de la correspondencia dirigida al Baltasar de Moscoso y Sandoval. En una de las cartas fechadas en noviembre de 1654, Francisco Rizi junto con Pedro de la Torre y Francisco Bautista, le exigieron:

Para que si avia persona que a mas de lo que esta echo en dicho modelo executado de madera se puede mejorar en partes o en el todo a lo cual respondo que en cuanto lo que está echo está

31 Wethey, 1956: 41-46.

32 Frutos 1654 / Gastos 1655, ACT, Obra y Fábrica, fol. 168 r.

${ }^{33}$ Díaz, 2010: 62; García, 2015:21.

${ }^{34}$ Escritura de concierto entre la fábrica catedralicia y Virgilio Fanelli. AHPT, Protocolo $\mathrm{n}^{\circ} 30278$, fols. 94 r. / 103 v. El proceso ejecutivo se dilató desde 1655 hasta julio de 1674, generando una abundante documentación conservada principalmente en el Archivo Capitular y el Archivo Histórico Provincial. Esta pieza junto con el resto de la producción artística de Virgilio Fanelli son objeto de estudio de mi tesis doctoral, dirigida por Manuel Pérez Hernández (profesor titular de Historia del Arte en la Universidad de Salamanca) y Palma Martínez-Burgos García (catedrática de Historia del Arte en la Universidad de Castilla-La Mancha). Al margen de los trabajos ya mencionados, es interesante destacar: CRUZ, 2000: 594; Díaz, 2014: 143-190. 
muy bueno, pero en cuanto el adornar lo revestirle mas al modelo de plateria, no tocando la planta ni en lo mayor, sino en los adornos, V.m tiene en la mano persona que lo adelantara por las obras q. le tengo vistas que son excelentes es Don Sebastian Herrera, que un modelo para plata no abra en España quien adelante ${ }^{35}$

El explícito mensaje no suscita dudas; el trío de artistas pretendía que Herrera Barnuevo fuese contratado a fin de enriquecer el exorno del trono, sin alterar la planta ni la estructura. Idéntica petición hizo el canónigo obrero cuando, al dirigirse al prelado por aquellas fechas, le suplicó la intervención del discípulo de Cano "para adornar el trono y su maior lucimiento" 36 . Este hallazgo permite conocer su verdadero papel en esta primera fase constructiva; al contrario de lo que se ha venido defendiendo, no elaboró una traza en oposición a la de Pedro de la Torre y Francisco Bautista, sino que fueron ellos, junto con Francisco Rizi, quiénes aconsejaron su participación.

Cerramos nuestro recorrido con unas breves pinceladas alusivas a la que hubo de ser la auténtica propuesta de Sebastián de Herrera Barnuevo, aquella que tan insistentemente se demandó desde la Dives Toletana. Desafortunadamente se desconoce su paradero, así como algún testimonio que informe en qué consistió y si fue o no aprobada por Baltasar de Moscoso y Sandoval ${ }^{37}$. Sea como fuere, lo cierto es que la comparación entre el modelo definitivo en papel y la obra en plata evidencia dos grandes diferencias localizadas en las cartelas de los frentes y en la clave del arco, con un notable aumento del corpus escultórico que se aleja de la simple propuesta inicial, especialmente con la inclusión de las escenas de San Ildefonso predicando frente a los herejes y La imposición de la Casulla. Así pues ¿hemos de responsabilizar al arquitecto madrileño de tal cambio? Sin duda, una pregunta con la que se abre un nuevo debate para cuya resolución habrá que esperar a futuras investigaciones ${ }^{38}$.

Finalmente, y volviendo a fray Antonio de Jesús María, en la concepción del majestuoso trono en plata dedicado a la Virgen del Sagrario sí participaron los cuatro artífices recogidos por el cronista, Alonso Cano, Pedro de la Torre, Francisco Bautista y Sebastián de Herrera Barnuevo. Nuestra aportación ha sido precisar el cometido de cada uno de ellos y las fechas exactas, de cara a resolver las dudas que presentaba este magnífico ejemplo de la platería barroca.

\section{BIBLIOGRAFÍA}

Antonio de Jesús María (1680): D. Baltasar de Moscoso i Sandoval, Presbytero Cardenal de la S.I.R. del titulo de Santa Cruz en Ierusalem, Arzobispo de Toledo..., canciller maior de Castilla, Madrid: Casa de Bernardo de Villa-Diego, impresor del Rey.

Bérchez Gómez, Joaquín (2002): "En defensa de Alonso Cano arquitecto". En: Symposium Internacional Alonso Cano y su época: Granada, 14-17 de febrero de 2002, Granada: Junta de Andalucía, Conserjería de Cultura, pp. 61-85.

${ }^{35}$ Memoria de los acuerdos para la ejecución del trono, ACT, Fondo de Secretaría, s/f.

${ }^{36}$ En el documento original se dice "Antonio de Herrera", lo que se trata de una confusión, pues se refieren a Sebastián con el nombre de su padre. Memoria de los acuerdos para la ejecución del trono, ACT, Fondo de Secretaría, s/f.

37 El ya citado Harold E. Wethey identificó, erróneamente, el supuesto modelo del trono presentado por Sebastián de Herrera Barnuevo ante la Catedral Primada con uno destinado a la Virgen de Atocha, hoy conservado en el Museo Nacional del Prado. A excepción de José Manuel Cruz Valdovinos y Juan Nicolau, quienes rechazaron la propuesta del hispanista, los trabajos concernientes a esta temática le han mostrado su apoyo incluso Alfonso Emilio Pérez Sánchez en el Catálogo de dibujos expuso que "es un obra muy bella y característica de Herrera Barnuevo, sin duda el proyecto que presentó en 1654 a la Catedral, para que fuera realizado en plata, sin conseguirlo". La equívoca identificación continuó hasta que Juan María Cruz Yábar pudo confirmar de manera categórica que dicho modelo pertenecía al trono en plata de la Virgen de Atocha, gracias a la escritura de concierto firmada por el que sería su autor, Juan Ortiz de la Rivilla. Véase en: Pérez, 1972: 7; Cruz, 1985: 1255; Cruz, 2010: 235-250.

38 En los últimos años han salido a la luz varios trabajos concernientes al trono catedralicio y su proceso ejecutivo que, pese a desvincularse del tema aquí propuesto, hemos creído interesante mencionar. Primeramente, aquel de Eduardo Lamas, donde se defiende la participación de Francisco Rizi en la concepción final de dicha pieza gracias a un conjunto de dibujos conservados en la Galería de los Uffizi. A este se unen dos más, en esta ocasión concernientes a un dibujo del trono realizado tras su conclusión, adquirido por el Museo del Prado en 2018. Véase Lamas, 2016: 221-222; Rodríguez, 2017: 130-132; Matilla, 2019: 64-65. 
Blanco Mozo, Juan Luis (2009): “Alonso Cano en Madrid: nuevas aportaciones, nuevos problemas”. En: Anuario del Departamento de Historia y Teoría del Arte, 21, Madrid, pp. 147-164.

Blasco Esquivias, Beatriz (2005): "Consideraciones sobre la universalidad de Alonso Cano (1601-1667) y su fama de arquitecto". En: Anales de Historia del Arte, 15, Madrid, pp. 127-150.

Blasco Esquivias, Beatriz (2013): Arquitectos y tracistas: el triunfo del Barroco en la Corte de los Austrias, Centro de Estudios de Europa Hispánica, Madrid.

Blasco Esquivias, Beatriz (2016):'Invención, traza y proyecto. El proceso arquitectónico en las Obras Reales de la Casa de Austria". En: Artigrama, 31, Zaragoza, pp. 279-306.

Bulgari, Constantino G. (1974): Argentieri, gemmari e orafi d'Italia, IV, Roma: Palombi Editori.

Cajés, Patricio (1593): Regla de las cinco órdenes de architectura; de Iacome de Vignola; agora de nueuo traduzido de Toscano en Romance por Patritio Caxesi Florentino, pintor y criado de su Mag, Madrid, casa del autor.

Chueca Goitia, Fernando (1969): "Alonso Cano y su influjo en la arquitectura barroca". En: Centenario de Alonso Cano en Granada. Estudios, Madrid: Ministerio de Educación y Ciencia, pp. 111-127.

Condorelli, Adele (1994): Dizionario Biografico degli italiani, vol.44, Roma: Istituto della Enciclopedia italiana.

Cruz Valdovinos, José Manuel (1985): “Arquitectura Barroca: siglo XVII”. En: Historia de la Arquitectura Española, Tomo IV, Zaragoza, 1985, p. 1253.

Cruz Valdovinos, José Manuel (2014): “Alonso Cano en Madrid”. En: Arte y cultura en la Granada renacentista y barroca: relaciones e influencias (coord. José Policarpo Cruz Cabrera), Granada: Universidad de Granada, pp. 191-222.

Cruz Yábar, Juan María (2010): "Juan Ortiz de la Rivilla y otros plateros en la capilla de Nuestra Señora de Atocha de Madrid”. En: Estudios de platería: San Eloy 2010, Murcia: Universidad de Murcia, pp. 235-250.

Cruz Yábar, Juan María (2015): “A Cano lo que es de Cano. Los contratos para el arco de la Puerta de Guadalajara de 1649 y su reconstrucción”. En: Anuario del Departamento de Historia y Teoría del Arte, 27, Madrid, pp. 117-141.

Díaz Fernández, Antonio José (2004): "Origen y presencia de la columna salomónica en el retablo barroco toledano". En: Toletum: boletín de la Real Academia de Bellas Artes y Ciencias Históricas de Toledo, 49, 2004, pp. 143-190.

Díaz García, Abraham (2010): "Sebastián de Herrera Barnuevo (1619-1671). Obra pictórica". En: Cuadernos de Arte e Iconografia, Tomo XIX, 37, Madrid.

Fernández Collado, Ángel / Rodríguez González, Alfredo / Castañeda Tordera, Isidoro (2009): Los diseños de la Catedral de Toledo: catálogo de diseños arquitectónicos, artísticos, topográficos y textiles, Toledo: Cabildo de la Catedral. Instituto Teológico San Ildefonso: Diputación Provincial de Toledo, pp. 22, 23 y 53.

García Zapata, Ignacio José (2015): “Alhajas, ropas y el trono de la Virgen del Sagrario, obra del platero italiano Virgilio Fanelli". En: Toletana: cuestiones de teología e historia, 29, pp. 273-307.

Lamas Delgado, Eduardo (2016). "Estudio para pedestal de escultura con putti”. En: I segni nel tempo. Dibujos españoles de los Uffizi, Navarrete Prieto, Benito (dir.) Alonso Moral, Roberto (col.), Madrid, Fundación MAPFRE.

Marías Franco, Fernando (1999): "Alonso Cano y la columna salomónica”. En: Figuras e imágenes del Barroco: estudios sobre el barroco español y sobre la obra de Alonso Cano, Madrid: Fundación Argentaria, pp. 291-322.

Martín González, Juan José (1958): “Arte y artistas del siglo XVII en la corte”. En: Archivo Español de Arte, 122, Madrid, pp. 125-142.

Matilla, José Manuel (2019): Memoria de Actividades 2018, Madrid: Museo del Prado, pp. 64-65.

Nicolau Castro, Juan (1996): "La maqueta del trono de la Virgen del Sagrario de la Catedral de Toledo". En: Academia: Boletín de la Real Academia de Bellas Artes de San Fernando, 83, Madrid, pp. 271-286.

Pérez Grande, Margarita (2004): "Las piezas de platería del Ayuntamiento de Toledo". En: Archivo Secreto: revista cultural de Toledo, 2, Toledo, pp. 118-147.

Pérez Sánchez, Alfonso Emilio (1972): Catálogo de dibujos. I. Dibujos españoles de los siglos XV-XVI-XVII, Madrid: Museo del Prado.

Perpiñá García, Candela (2011): "Los ángeles músicos: estudios de los tipos iconográficos de la narración evangélica". En: Anales de Historia del Arte, 1, Madrid, pp. 397-411.

Perpiñá García, Candela (2013): "Música angélica en la imagen mariana. Un discurso visual sobre la esperanza de salvación". En: ACTA ARTIS: Estudis d'Art Modern, 1, Barcelona, pp. 29-49.

Ramírez de Arellano, Rafael (1915): Estudio sobre la historia de la orfebrería toledana, Toledo: Imprenta Provincial.

Rodríguez G. de Ceballos, Alfonso (2001): “Alonso Cano, arquitecto artista”. En: Archivo español de arte, Vol. 74, 296, Madrid, pp. 375-392.

Rodríguez Rebollo, Ángel (2017): “Traza para el trono de la Virgen del Sagrario de la catedral de Toledo”. En: Artur Ramón Art, Barcelona, pp. 130-132.

Sánchez Esteban, Natividad (2001): “Artistas y arquitectos. Alonso Cano y sus dibujos de arquitectura”. En: Alonso Cano. Dibujos. Madrid: Museo Nacional del Prado, pp. 57-73.

Tovar Martín, Virginia (1973): "El arquitecto-ensamblador Pedro de la Torre". En: Archivo Español de Arte, Tomo 46, 183, pp. 261-298.

Wethey, Harold E. (1956). "Decorative projects of Sebastian de Herrera Barnuevo". En: Burlington Magazine, 98, Londres, pp. 41-46.

Fecha de recepción: 29-V-2020

Fecha de aceptación: 17-VII-2020

Archivo Español de Arte, vol. XCIII, n. ${ }^{\circ} 372$, pp. 347-358, octubre-diciembre 2020 ISSN: 0004-0428, eISSN: 1988-8511, https://doi.org/10.3989/aearte.2020.23 